\title{
Poxvirus K7 Protein Adopts a Bcl-2 Fold: Biochemical Mapping of Its Interactions with Human DEAD Box RNA Helicase DDX3
}

\author{
Arnout P. Kalverda ${ }^{1} \dagger$, Gary S. Thompson ${ }^{1} \dagger$, Andre Vogel $^{2}$, \\ Martina Schröder ${ }^{2}$, Andrew G. Bowie ${ }^{2}$, Amir R. Khan ${ }^{2 \star}$ \\ and Steve W. Homans ${ }^{1 *}$
}

\author{
${ }^{1}$ Astbury Centre for Structural \\ Molecular Biology, University of \\ Leeds, Leeds LS2 9JT, UK
}

${ }^{2}$ School of Biochemistry and Immunology, Trinity College Dublin, Dublin 2, Ireland

Received 28 April 2008; received in revised form 20 August 2008; accepted 17 September 2008

Available online

27 September 2008
Poxviruses have evolved numerous strategies to evade host innate immunity. Vaccinia virus K7 is a 149-residue protein with previously unknown structure that is highly conserved in the orthopoxvirus family. $\mathrm{K} 7$ bears sequence and functional similarities to A52, which interacts with interleukin receptor-associated kinase 2 and tumor necrosis factor receptor-associated factor 6 to suppress nuclear factor $\mathrm{kB}$ activation and to stimulate the secretion of the anti-inflammatory cytokine interleukin-10. In contrast to A52, K7 forms a complex with DEAD box RNA helicase DDX3, thereby suppressing DDX3-mediated ifnb promoter induction. We determined the NMR solution structure of $\mathrm{K} 7$ to provide insight into the structural basis for poxvirus antagonism of innate immune signaling. The structure reveals an $\alpha$-helical fold belonging to the Bcl-2 family despite an unrelated primary sequence. NMR chemical-shift mapping studies have localized the binding surface for DDX3 on a negatively charged face of K7. Furthermore, thermodynamic studies have mapped the K7-binding region to a 30-residue N-terminal fragment of DDX3, ahead of the core RNA helicase domains.

(C) 2008 Elsevier Ltd. All rights reserved.

Keywords: K7 protein; DDX3 helicase; Bcl-2; nuclear magnetic resonance (NMR) spectroscopy; innate immunity

\section{Introduction}

Poxviruses are large double-stranded DNA viruses encoding $\sim 200$ genes that replicate in the cytoplasm of host cells. ${ }^{1}$ Members of this family include vaccinia (VACV) and variola virus, the causative agent of smallpox. In addition to viral RNA/DNA polymerases and virion assembly proteins, poxviruses encode proteins such as A46 and A52 that antagonize host immunity. Previous studies of pox-

${ }^{*}$ Corresponding authors. E-mail addresses:

amirrafk@tcd.ie; s.w.homans@leeds.ac.uk.

$\uparrow$ A.P.K. and G.S.T. contributed equally to this work.

Abbreviations used: VACV, vaccinia virus; NF- $\kappa B$, nuclear factor $\kappa \mathrm{B}$; TLR, Toll-like receptor; TRAF6, tumor necrosis factor receptor-associated factor 6; IRAK2, interleukin receptor-associated kinase 2; mRNA, messenger RNA; HSQC, heteronuclear single quantum coherence; NOE, nuclear Overhauser enhancement; RDC, residual dipolar coupling; Bcl-2, B-cell lymphoma protein2; rTEV, recombinant tobacco etch virus. virus antagonism of immune signaling were instrumental in revealing the critical role of Toll-like receptors (TLRs) in the antiviral state. ${ }^{2}$ Originally identified as mediators of innate immunity against bacterial pathogens, TLRs are a family of single-span membrane proteins whose extracellular regions consist of leucine-rich repeats that bind pathogenassociated molecular patterns such as lipopolysaccharides and double-stranded RNA. ${ }^{3}$ Recent crystal structures of the ectodomain of TLRs alone and in complex with a triglyceride agonist suggest a model for oligomerization that triggers a complex intracellular signaling cascade leading to nuclear factor $\kappa \mathrm{B}$ $(\mathrm{NF}-\kappa \mathrm{B})$ activation, altered gene expression and inflammation. ${ }^{4}$ Inappropriate activation of TLRs is implicated in a variety of pathological conditions, such as autoimmune disease (arthritis, asthma, systemic lupus erythromatosis), the allergic reaction, sepsis and type I diabetes. ${ }^{5}$

Biochemical and cellular studies of two VACV proteins, A46 and A52, revealed that they contribute to virulence by antagonizing TLR-dependent signaling pathways. ${ }^{6,7}$ A52 interacts with components of the 
TLR signaling cascade, namely, tumor necrosis factor receptor-associated factor 6 (TRAF6) and interleukin receptor-associated kinase 2 (IRAK2). Binding to TRAF6 mediates p38 mitogen-activated protein kinase activation and induction of the anti-inflammatory cytokine interleukin-10, while the interaction with IRAK2 leads to inhibition of both NF-кB activation and subsequent release of pro-inflammatory cytokines. $^{2}$ VACV protein K7 is highly conserved in the poxvirus family and has $25 \%$ identity (50\% homology) to A52. Both are also predicted to form predominantly $\alpha$-helices by secondary-structure algorithms. Recent co-immunoprecipitation experiments in the laboratory of one of the authors have shown that K7 also interacts with TRAF6 and IRAK2. ${ }^{8}$ However, in striking contrast to A52, K7 forms a complex with DEAD box RNA helicase DDX3. ${ }^{8}$

Functionally, RNA helicases are described as adenosine triphosphate (ATP)-dependent motor proteins that unwind double-stranded nucleic acids. ${ }^{9}$ Structurally, RNA helicases share a conserved catalytic core that comprises tandem RecA-like domains. The ATP-binding groove is mainly formed by the $\mathrm{N}$-terminal domain, but the mature catalytic machinery involves an intimate association of the two domains around the ATP pocket. The RNA binding site stretches across the two domains in the active conformation of RNA helicases. The catalytic machinery includes the eponymous 'D-E-A-D/H' sequence in 'superfamily 2 ' to which DDX3 belongs, adjacent to the phosphate arm of ATP. ${ }^{10}$ Hydrolysis of ATP is stimulated by cycles of binding and release of RNA molecules. ${ }^{11}$ The biological functions of the $\sim 45$ RNA helicases in the human genome are diverse and poorly characterized. They have been implicated in multiple aspects of RNA metabolism at the level of transcription, translation, messenger RNA (mRNA) transport and stability. Indeed some of the functions of RNA helicases may not be linked to enzymatic activity at all. Recent structural and functional studies of eIF4AIII, a component of the exon junction complex, demonstrate that the RNA helicase acts as a 'placeholder' for nascent RNA molecules and shuttles them from the nucleus to the cytosol. ${ }^{12}$ Outside of the RecA-like domains, the sequences and domain organization of RNA helicases are highly heterogenous in size and composition, likely reflecting their diverse roles in cellular processes.

Both K7 and A52 bear no apparent sequence similarities to proteins whose three-dimensional structures are known. Here we describe the NMR solution structure of $\mathrm{K} 7$ and map its interactions with DDX3 in order to gain insight into the molecular basis for poxvirus antagonism of innate immune signaling.

\section{Results}

\section{Solution structure of K7R}

To determine the structure of $\mathrm{K} 7$ by NMR, we chose to work on a fragment $(\mathrm{K} 7 \Delta 8,8-149)$ that was slightly truncated at the $\mathrm{N}$-terminus (hereafter termed K7), thus yielding considerably better NMR spectra than the full-length construct. Using multidimensional NMR spectroscopy, we obtained $\left({ }^{1} \mathrm{H}\right.$, ${ }^{13} \mathrm{C},{ }^{15} \mathrm{~N}$ ) assignments of 135 out of 142 residues for the backbone and $87 \%$ of the side-chain resonances of K7. Cross peaks in the ${ }^{1} \mathrm{H}-{ }^{15} \mathrm{~N}$ heteronuclear single quantum coherence (HSQC) for one of the regions in the protein (residues 116-128, $\alpha 5-\alpha 6$ loop) were relatively weak. In this region, peaks for residues F122, Q123, S124, L125 and I128 were missing from the spectra and could not be assigned, suggesting conformational exchange. Similarly, two residues (N88 and H93) in the $\alpha 3-\alpha 5$ loop region could not be assigned. This loop lacks an $\alpha$-helical conformation, in contrast to known structures of viral and cellular B-cell lymphoma protein-2 (Bcl-2) family of proteins (discussed below). Structures were calculated with 2892 nuclear Overhauser enhancement (NOE) restraints, 182 dihedral angle restraints and 71 residual dipolar coupling (RDC) restraints (Table 1). For the final ensemble of 15 structures, the rmsd of backbone atoms from the mean structure was $0.33 \AA$ (Fig. 1 and Supplementary Fig. S1).

The overall fold of $\mathrm{K} 7$ consists of a bundle of six $\alpha$-helices and connecting loops that match the topology of the Bcl-2 family of proteins that regulate apoptosis (Fig. 1). The structure of K7 closely resembles the X-ray crystal structure of poxvirus protein N1

Table 1. NMR and refinement statistics for protein structures

\begin{tabular}{|c|c|}
\hline & K7(8-149) \\
\hline \multicolumn{2}{|l|}{ NMR distance and dihedral constraints } \\
\hline \multicolumn{2}{|l|}{ Distance constraints } \\
\hline Total NOE & 2892 \\
\hline Intraresidue & 1440 \\
\hline Interresidue & 1452 \\
\hline Sequential $(|i-j|=1)$ & 737 \\
\hline Medium-range $(|i-j| \leq 4)$ & 348 \\
\hline Long-range $(|i-j| \geq 5)$ & 367 \\
\hline \multicolumn{2}{|l|}{ Intermolecular } \\
\hline Total RDCs & 71 \\
\hline${ }^{1} \mathrm{D}_{\mathrm{HN}}$ & 71 \\
\hline Total dihedral angle restraints & 182 \\
\hline$\phi$ & 91 \\
\hline$\psi$ & 91 \\
\hline \multicolumn{2}{|l|}{ Structure statistics } \\
\hline \multicolumn{2}{|l|}{ Violations (mean and s.d.) } \\
\hline Distance constraints $(\AA)$ & $0.0234 \pm 0.0007$ \\
\hline Dihedral angle constraints $\left(^{\circ}\right)$ & $0.11 \pm 0.47$ \\
\hline Max. dihedral angle violation $\left(^{\circ}\right)$ & 6.123 \\
\hline Max. distance constraint violation $(\AA)$ & 0.422 \\
\hline RDC Q & $0.28 \pm 0.024$ \\
\hline Average RDC violation $\left(^{\circ}\right)$ & $0.60 \pm 0.80$ \\
\hline \multicolumn{2}{|l|}{ Deviations from idealized geometry } \\
\hline Bond lengths $(\AA)$ & $0.0062 \pm 0.00018$ \\
\hline Bond angles $\left({ }^{\circ}\right)$ & $0.71 \pm 0.02$ \\
\hline & $1.71 \pm 0.09$ \\
\hline \multicolumn{2}{|l|}{ Average pairwise rmsd* $(\AA)$} \\
\hline Heavy & 0.750 \\
\hline Backbone & 0.330 \\
\hline
\end{tabular}

*Pairwise rmsd's were calculated over structured regions from an ensemble of 15 structures superimposing the restrained residues in the molecule $(8-82,95-115,129-148)$. 
(a)

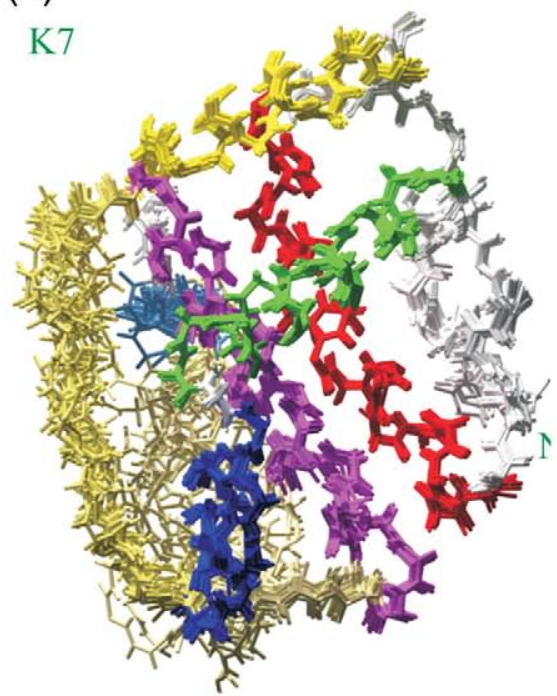

(c)

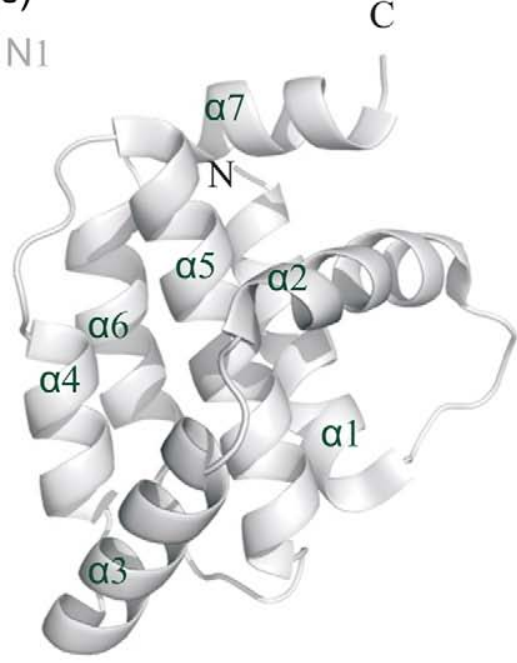

(b)

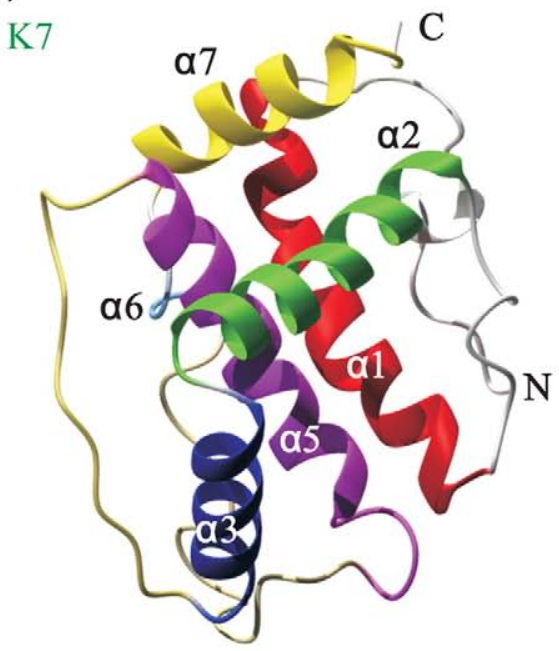

(d)

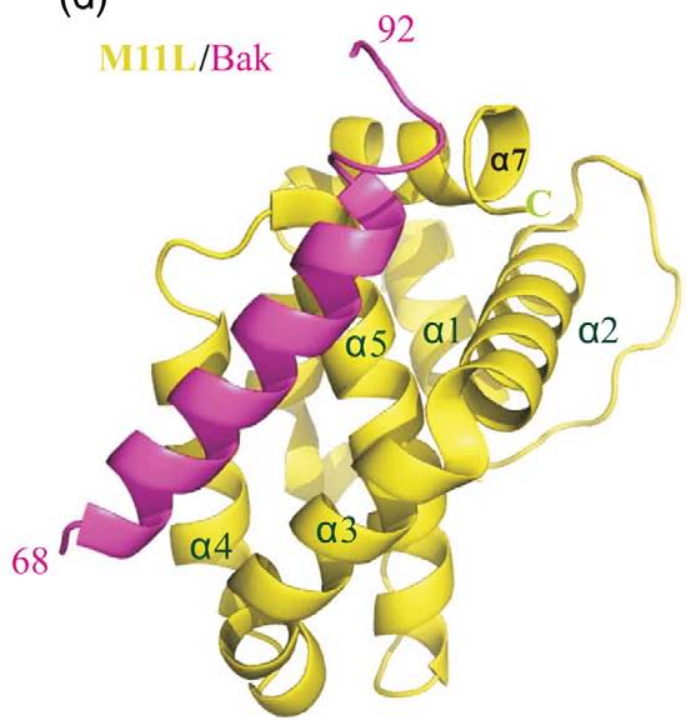

Fig. 1. Solution structure of $\mathrm{K} 7$ and comparisons to the viral Bcl-2 family. (a) Best-fit superposition of 15 final structures showing backbone bonds. (b) Ribbon model of the lowest-energy structure from the ensemble showing the six $\alpha$-helices of K7 with Bcl-2 topology labels. The secondary-structure regions are helix 1 (23-43), helix 2 (52-68), helix 3 (70-82), helix 5 (95-115), helix 6 (129-147) and helix 7 (134-147). The disordered regions correspond to residues 83-94 and 116-128 ( $\alpha 5-\alpha 6$ loop). (c) Poxvirus N1 protein (PDB code 2i39) is the closest structural relative of K7. (d) Myxoma virus M11L protein (yellow, PDB code 2jby) in complex with a 26-mer BH3 peptide from Bak (magenta). Coordinates of K7 have been deposited in the Protein Database and BioMagResBank, accession numbers $2 \mathrm{k} 36$ and 15740, respectively. We have maintained the canonical Bcl-2 nomenclature for the $\alpha$-helices that follow loop 84-93 of K7 in order to avoid confusion in discussions in the text.

recently determined by two independent groups. ${ }^{13,14}$ The fold consists of a central $\alpha$-helix $(\alpha 5)$ surrounded by a layer of additional $\alpha$-helices. More important, K7 is flexible and lacks secondary structure in the region 84-93, which corresponds to $\alpha 4$ in all known viral and cellular members of the Bcl-2 family. This flexibility in K7 may have functional implications (discussed below), since $\alpha 4$ in other viral Bcl-2 homologs forms one wall of a groove that binds to pro-apoptotic BH3-containing proteins. We have maintained the canonical Bcl-2 nomenclature for the $\alpha$-helices that follow loop $84-93$ of K7 in order to avoid confusion in the ensuing discussions.
The 149-residue K7 has a lengthy prelude to the first $\alpha$-helix, relative to N1. This region (residues 8 23) lacks regular secondary structure, and residues 8-11 show significant flexibility despite modest interactions with $\alpha 1$ and the $\alpha 1-\alpha 2$ loop. Following least-squares superposition using a secondary- structure matching algorithm implemented in CCP $4 \mathrm{mg}^{15}$ K7 most closely resembles N1 (rmsd $=2.38 \AA$ for 101 $\mathrm{C}^{\alpha}$ atoms). Upon superposition of $\mathrm{K} 7$ and $\mathrm{Bcl}-2$ [Protein Data Bank (PDB) code 1PQ1], the rmsd for $90 \mathrm{C}^{\alpha}$ atoms is $3.8 \AA$. The N-terminal extension of K7 accounts for the difference in sequence length between K7 (149 residues) versus N1 (115 residues). 


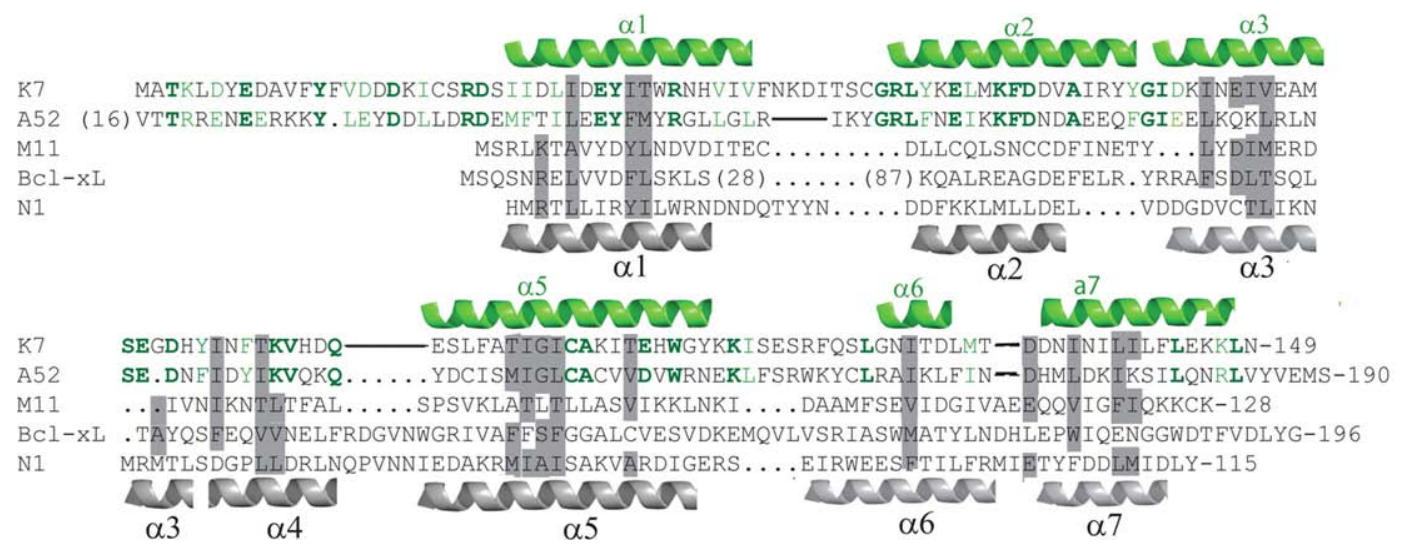

Fig. 2. Structure-based sequence alignment of viral and cellular Bcl-2 family proteins. The green ribbons correspond to K7, while grey ribbons mark the structure of N1. Residues conserved between K7 and A52 are highlighted in light and dark green. Dashed lines are consecutive residues, while dots mark regions with insertions, with the major one in Bcl- $\mathrm{x}_{\mathrm{L}}$ indicated by sequence numbers.

Myxoma virus protein M11L, whose structure was determined in the absence and in the presence of the $\mathrm{BH} 3$ peptide from Bak, ${ }^{16}$ is another member of the extended family of viral Bcl-2 proteins. Finally, the crystal structure of herpesvirus M11L was recently determined in complex with a fragment of proautophagic Beclin1. ${ }^{17}$ The structural similarities between viral proteins $\mathrm{K} 7, \mathrm{~N} 1, \mathrm{M} 11$ and M11L are striking despite the lack of significant sequence identities (Figs. 1 and 2).

\section{$\mathrm{K} 7$ is a monomer with a closed $\mathrm{BH} 3$ groove}

The Bcl-2 family of proteins regulate apoptotic pathways by forming oligomeric complexes via the presence of varying numbers of Bcl-2-homology regions (BH1-BH4). ${ }^{18}$ For example, Bim (a BH3-only protein) adopts an $\alpha$-helical conformation in its $\mathrm{BH} 3$ segment and interacts with the hydrophobic groove on Bcl-xL, formed by $\alpha 2, \alpha 3, \alpha 4$ and the 'NWGR' motif at the beginning of $\alpha 5$. $^{19}$ This groove is also conserved in the two known structures of poxvirus Bcl-2 family homologs, N1 and M11. The crystal structure of M11L-Bak revealed that, in general, the mode of binding was conserved despite sequence differences, as exemplified by the lack of the characteristic NWGR motif.

Although the structure of N1 in complex with proapoptotic Bcl-2 proteins has not yet been determined, biochemical studies have confirmed that N1 interacts with Bad, Bax and Bid. ${ }^{13}$ Notably, hydrophobic residues in the presumed groove (Leu27, Leu52) are conserved with the Bcl-2 family. Following structural alignment, the $\mathrm{BH} 3$ groove of $\mathrm{N} 1$ reveals an open conformation that is poised for interactions with its cognate proteins (Fig. 3). The hydrophobic dyad corresponds to residues Leu57 and Ile76 in K7, implying that a hydrophobic patch is conserved within
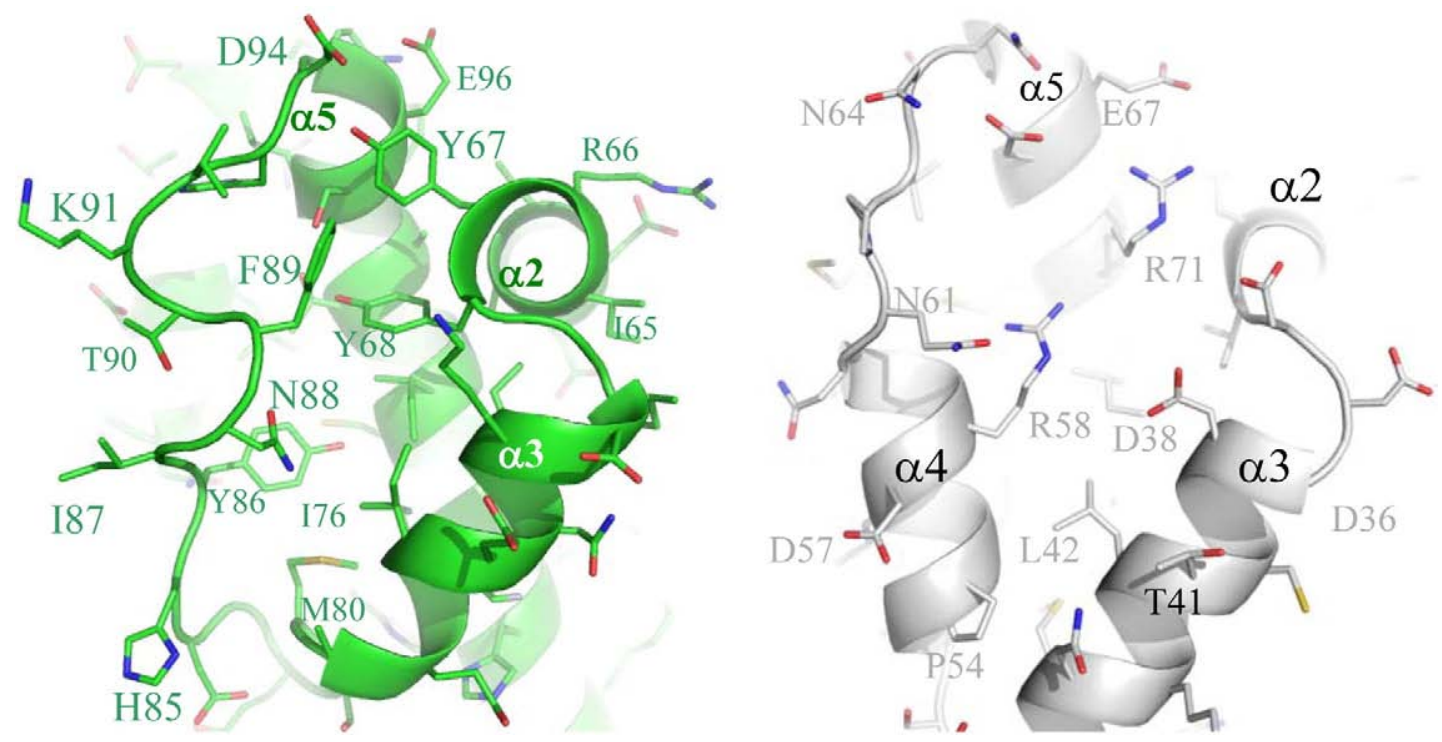

Fig. 3. The $\mathrm{BH} 3$ groove of $\mathrm{K} 7$ is filled with hydrophobic side chains. The orientation is the same as in Fig. 1 . K7 is coloured green, and N1 is grey. Side chains are represented as stick models to emphasize BH3 groove closure by Y67, Y68, and F89 in K7. The N1 surface is relatively open, although Arg58 of $\alpha 4$ resides along one wall of the BH3 groove. 
this region. However, in striking contrast to the extended Bcl-2 family, the NMR structure of K7 reveals a closed groove that is incompatible with binding of $\alpha$-helical BH3 domains (Fig. 3). Relative to N1, closure of the groove in $\mathrm{K} 7$ is a consequence of the longer $\alpha 2$ helix and its orientation, which effectively seals the pocket at the position where the C-terminal end of the $\mathrm{BH} 3$ helix would reside. Thus, although the residues flanking the groove are unstructured and undergo picosecond-nanosecond and millisecond dynamics, binding of $\mathrm{BH} 3$ domains would require a major rearrangement of the side chains of Y67 and Y68 and movement of the unstructured loop 82-94 away from the conformational space taken up in the structure ensemble. In further contrast to N1, K7 is a monomer in solution, forming a 1:1 stoichiometric complex with its effector DDX3 (Fig. S2). Intriguingly, the segment Asp84-His93 appears to be in conformational flux in $\mathrm{K} 7$, whereas other Bcl-2 family members adopt a helical conformation $(\alpha 4)$ that forms one wall of the $\mathrm{BH} 3$ groove. The sequence of this region is highly conserved between $\mathrm{K} 7$ and A52 (Fig. 2), suggesting that this segment may indeed be involved in protein-protein interactions, but distinct from the mode of recognition seen in the Bcl-2 family.

\section{Backbone dynamics of $\mathrm{K} 7$}

${ }^{15} \mathrm{~N}$ NMR relaxation measurements were performed on $\mathrm{K} 7$ to examine picosecond-nanosecond backbone dynamics, resulting in ${ }^{15} \mathrm{~N} R_{1}, R_{2}$ and ${ }^{15} \mathrm{~N}$ NOE values shown in Fig. 4. Smaller ${ }^{15} \mathrm{~N}$ NOE values for residues 8-11 are consistent with a disordered $\mathrm{NH}_{2}$ terminus obtained in the NMR solution structure. Moreover, increased $R_{2}$ relaxation rates are evident for residues 80-83, 90-91, 94-98, 109-118 and 129 (relaxation data could not be obtained for residues 85-89, 92-93 and 119-128 because of overlap or absent peaks), suggesting conformational exchange on the millisecond time scale. These residues are in loop regions and are consistent with disorder observed in the NMR solution structure (Fig. 1 and Supplementary Fig. S1).

As discussed previously, the $\alpha 3-\alpha 5$ loop of $\mathrm{K} 7$ (residues 83-94) lacks regular secondary structure. Analyses of the chemical shifts of residues in this loop show no indication of an $\alpha$-helical conforma-
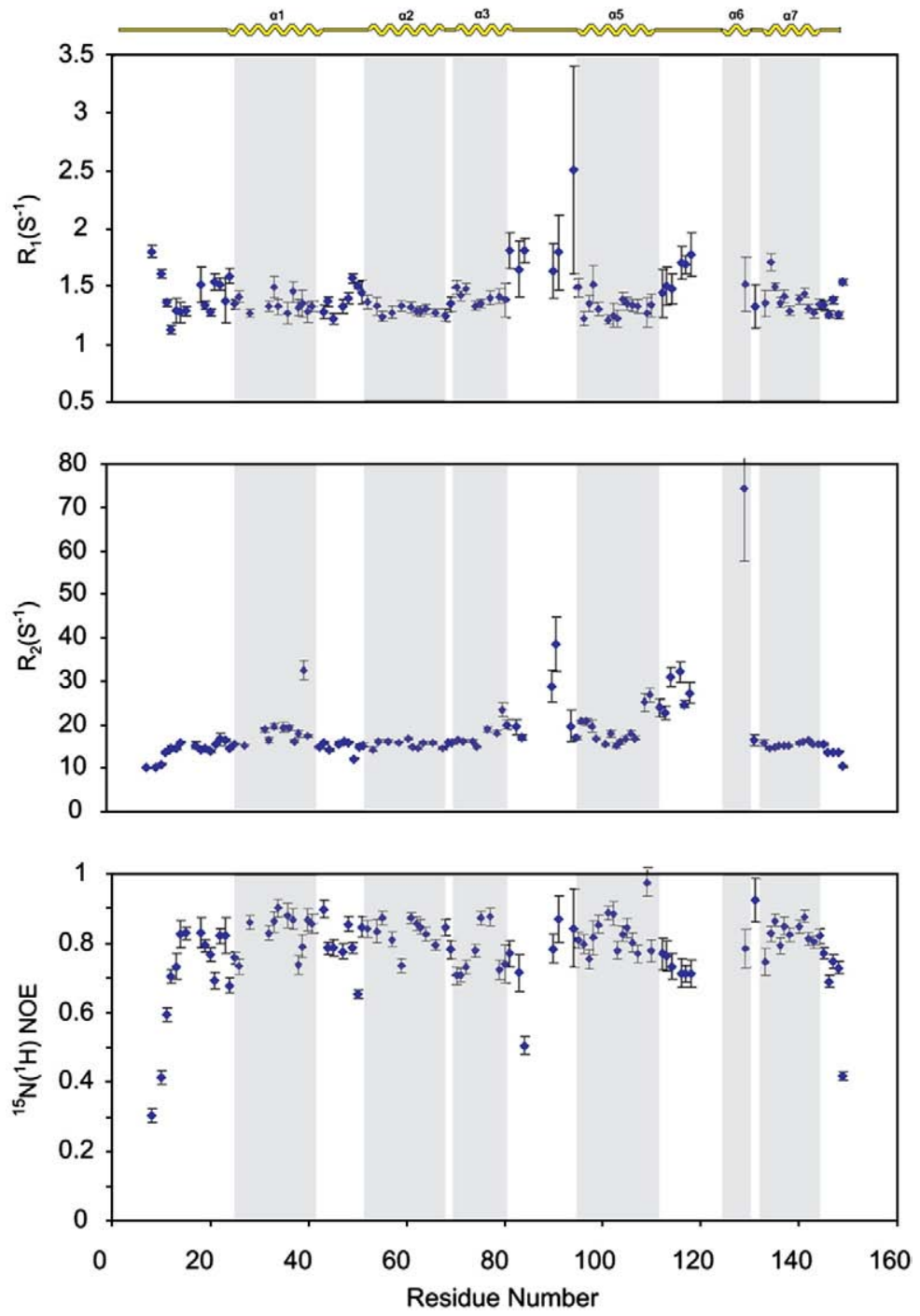

Fig. 4. Backbone dynamics of $\mathrm{K} 7$ (a) ${ }^{15} \mathrm{~N}$ longitudinal relaxation rates $\left(R_{1}\right)$; (b) ${ }^{15} \mathrm{~N}$ transverse relaxation rates $\left(R_{2}\right) ;(\mathrm{c}){ }^{15} \mathrm{~N}\left\{{ }^{1} \mathrm{H}\right\}$ NOEs for each residue in $\mathrm{K} 7$. Secondary structured regions are show as ribbons above the first panel above and as grey bleeds on the graphs. 
tion. Elevated $R_{1}$ rates and lower ${ }^{15} \mathrm{~N}\left\{{ }^{1} \mathrm{H}\right\}$ NOE values measured in the loop 83-94 show that nanosecond time scale internal motions are also present, suggesting that $\mathrm{K} 7$ has substantial flexibility in this region relative to other viral and cellular $\mathrm{Bcl}-2$ proteins.

\section{Mapping of K7 interactions with human RNA helicase DDX3}

Prompted by the observation that $\mathrm{K} 7$ binds to human RNA helicase DDX3 in VACV-WR infected cells, ${ }^{8}$ we mapped the interactions between K7 and DDX3 using a combination of deletion analyses, in vitro pull-down assays, co-purification procedures and NMR. Deletion of the N-terminal $\sim 166$ residues of DDX3 preceding the core helicase domains (167-580) eliminated K7 binding (data not shown). Inclusion of the upstream 'flanking sequence' that corresponds to two short $\alpha$-helices in Drosophila Vasa helicase ${ }^{17,20}$ (DDX3 construct 139-572) similarly did not reconstitute binding to $\mathrm{K} 7$, thus pointing to an important epitope in the first 139 residues of DDX3. This finding was supported by successful purification of DDX3 ${ }_{5-167}$ (fragment 5-167) in complex with $\mathrm{K} 7$ by size-exclusion chromatography (Fig. 5). This region is unique to DDX3 and bears no significant similarities to other helicases or proteins in various databases. Inspection of the amino acid composition of this segment implies a largely unstructured polypeptide, given the prevalence of polar and charged amino acids and the presence of 22 Gly residues.
The residues in $\mathrm{K} 7$ that interact with DDX3 were mapped by a variant of NMR chemical shift mapping, ${ }^{21,22}$ which calculates minimal chemical shift changes. This strategy was adopted because the two proteins form a tight complex in slow exchange on the NMR time scale, and the direction of the chemical shift changes could not be followed with a titration. In this case, the minimal chemical shift changes to translate the peak list for the ${ }^{15} \mathrm{~N}-{ }^{1} \mathrm{H}$ HSQC spectrum of uncomplexed $\mathrm{K} 7$ into a peak list compatible with the spectrum of the K7R/DDX3 ${ }_{5-167}$ complex were calculated (Fig. 6). For signals that have clearly moved between the free protein and the complex, the chemical shift difference to the nearest cross peak places a lower bound on the chemical shift change. These studies indicated that DDX3 binds across a shallow groove along $\alpha 1$ and between the ordered part of the N-terminus and the $\alpha 5-\alpha 6$ loop (Fig. 6). In this figure, the orientation of the molecules are rotated $180^{\circ}$ away from those in Fig. 1, along the vertical axis. This region corresponds to the homodimerisation interface of N1, which is mediated by $\alpha 1$ and $\alpha 6$. The negatively charged character of the corresponding K7 face may preclude dimer formation through electrostatic repulsions.

Given the apparent non-globular nature of the $\mathrm{N}$-terminus of DDX3 from sequence analyses, we hypothesized that $\mathrm{K} 7$ binds to a short stretch of DDX3 polypeptide. A series of 30-residue non-overlapping peptides of DDX3 were synthesized to narrowly define the K7-binding region. The five DDX3 peptides 1-30, 31-60, 61-90, 91-120 (not shown) and 121-150 were each synthesized with a

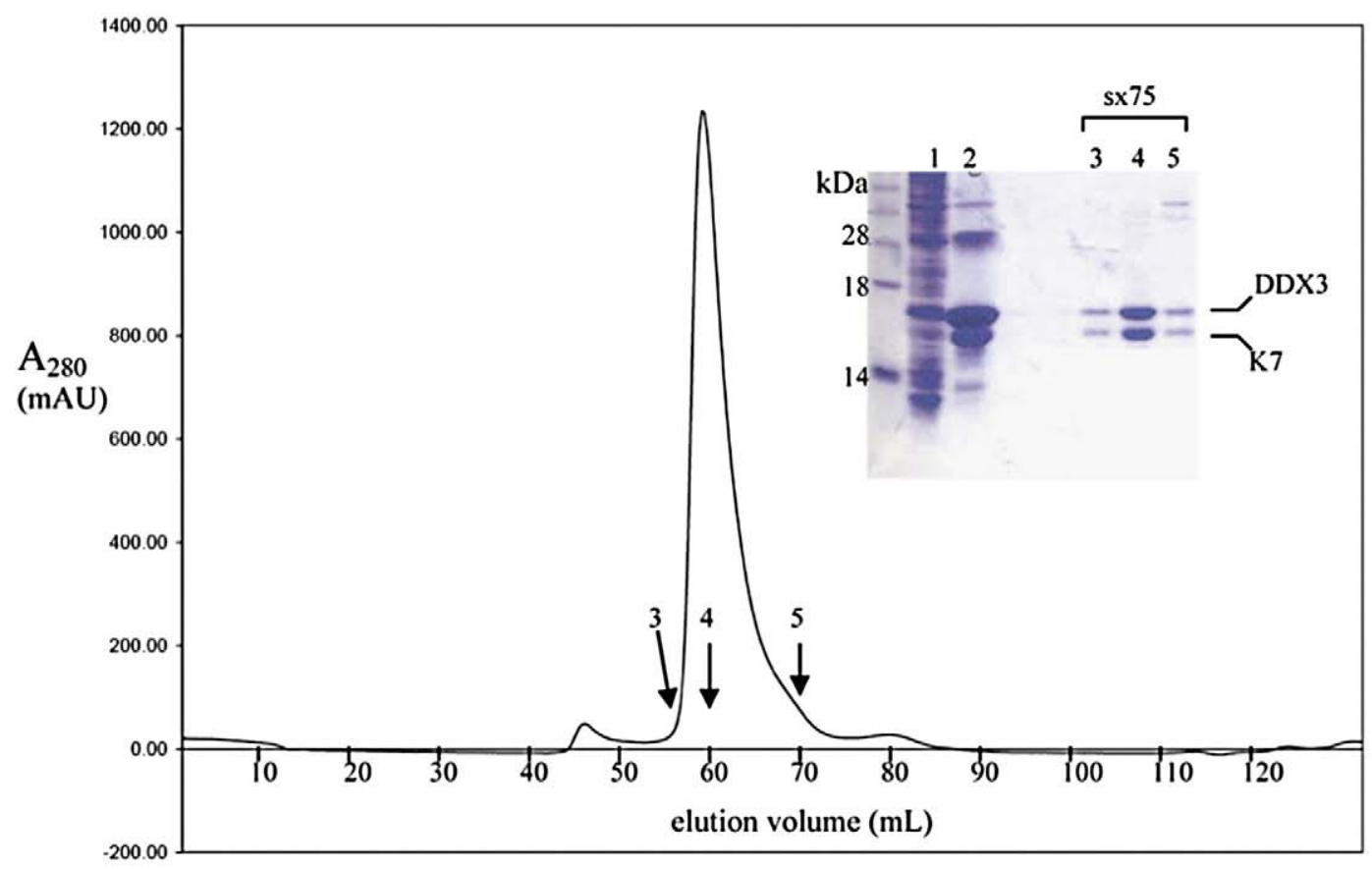

Fig. 5. Purification of the K7-DDX3 complex by size-exclusion chromatography. The DDX $3_{5-167}$ fragment was purified together with K7 using a Superdex-75 (sx75) column, as described in Materials and Methods. Inserted panel: SDSPAGE analyses of the purification steps, visualized with Coomassie Brilliant Blue. Lane 1, crude lysate of DDX3 $3_{5-167}$ following induction of protein expression. Lane 2, affinity-purified DDX3 and K7, incubated together prior to gel filtration. Lanes 3-5, fractions from the main peak following sx75 gel filtration. 

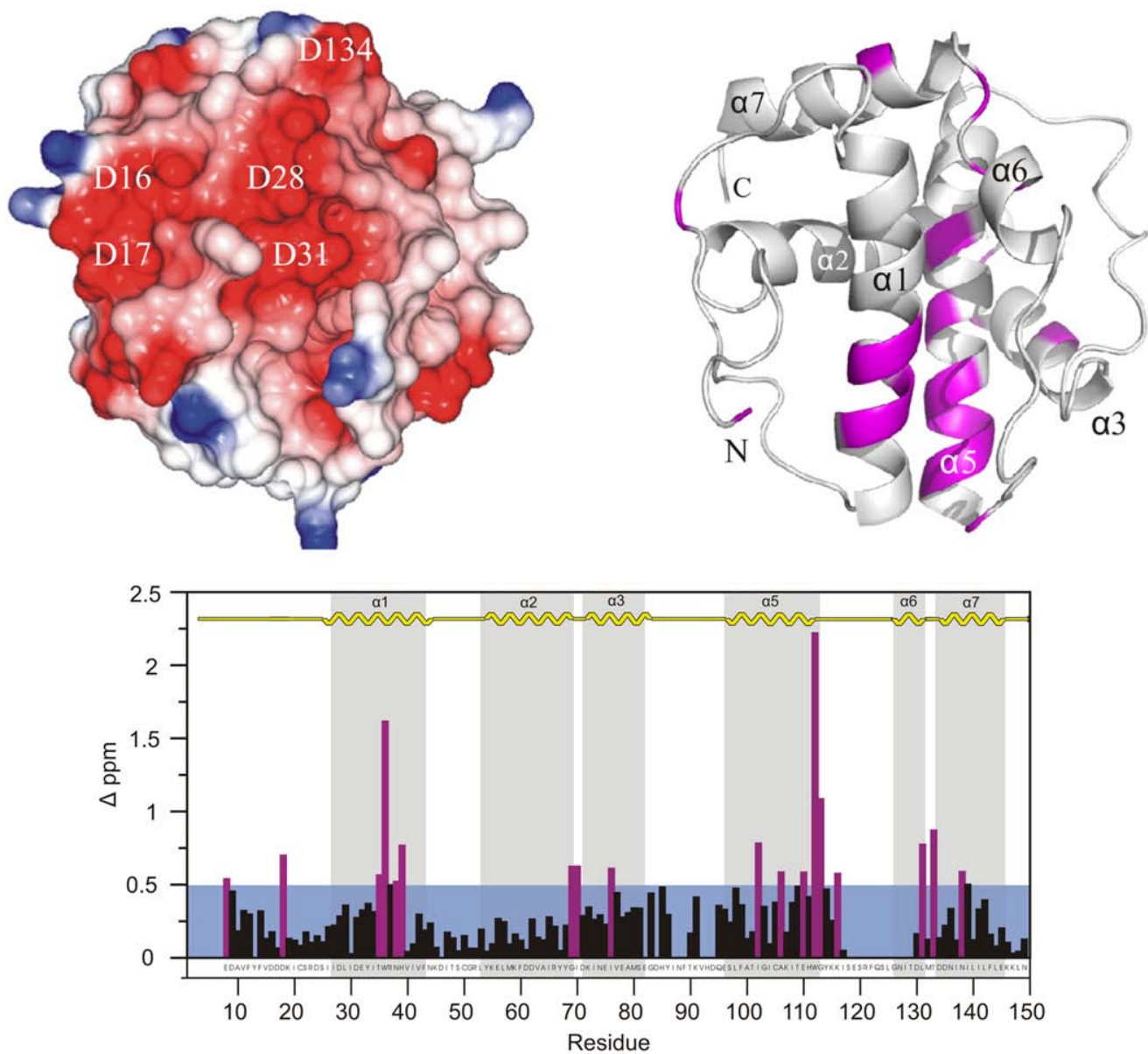

Fig. 6. Identification of the DDX3-binding face of $\mathrm{K} 7 \mathrm{by}{ }^{1} \mathrm{H}-{ }^{15} \mathrm{~N}$ HSQC chemical shift mapping. The orientation of these models is rotated $180^{\circ}$ along the vertical axis relative to Fig. 1. Left, electrostatic surface map of K7 revealing the density of negatively charged residues on this face. Right, ribbon model of the DDX3-binding region of K7 deduced from ${ }^{1} \mathrm{H}-{ }^{15} \mathrm{~N}$ HSQC spectra. Surfaces patches close to residues with a change in the shift metric $\Delta>0.5 \mathrm{ppm}$ are colored in magenta. Bottom, a graph of the shift metric $\Delta$ for all residues in K7. Secondary-structure elements are shown at the top of the panel and as grey bleeds on the graph. The sequence of K7 is shown at the bottom of the panel. The values of the shift metric $\Delta$ are shown as a bar chart, with the cutoff region $\Delta<0.5 \mathrm{ppm}$ shown in blue and residues with $\Delta>=0.5 \mathrm{ppm}$ shown with their bars colored magenta.

hexahistidine tag at their $\mathrm{N}$-termini to facilitate $\mathrm{Ni}^{2+}-$ agarose pull-down experiments with untagged $\mathrm{K} 7$. Only DDX3 peptide 61-90 was able to pull-down $\mathrm{K} 7$, revealing an important epitope for $\mathrm{K} 7$ binding in this region (Fig. 7). This segment of DDX3 is enriched in positively charged residues (Lys+Arg, six total) and serine residues. Isothermal titration calorimetry (Fig. 8) revealed a $K_{\mathrm{d}}=228 \mathrm{nM}$ for the interaction between the DDX3 $3_{61-90}$ peptide and $\mathrm{K} 7$, which is only modestly weaker than the longer N-terminal fragment DDX3 ${ }_{5-167}\left(K_{\mathrm{d}}=109 \mathrm{nM}\right)$.

\section{Discussion}

The NMR solution structure of $\mathrm{K} 7$ reveals that it belongs to the $\mathrm{Bcl}-2$ family. Despite this structural similarity there is no apparent functional conservation between $\mathrm{K} 7$ and the viral and cellular Bcl-2 family members (Fig. 9). In K7, the corresponding $\mathrm{BH} 3$ peptide-binding region is occluded by the length and orientation of the $\alpha 2$ helix, and the typi- cally shallow groove is filled with aromatic residues. This would make it impossible for $\mathrm{K} 7$ to bind to helical peptides in a fashion similar to that of Bcl-2 family proteins. It is evident that $\mathrm{K} 7$ belongs to a growing population of small helical immune evasion' proteins (A52, N1 and M11, M11L) that are functionally distinct but share an ancestral fold that is related to the cellular Bcl-2 family. In the case of N1, M11 and M11L, the capacity to bind BH3 helices is retained, and they have roles in the modulation of host apoptosis. K7 described here and the structurally related A52 antagonize host immunity by forming protein-protein complexes with multiple cellular partners. K7 binding to a distinct subset of effectors (e.g., DDX3) may partly be rationalized by its monomeric state, which opens the possibility of an additional face for protein-protein interactions relative to dimeric Bcl-2 family proteins.

Our data suggest that the primary binding site for $\mathrm{K} 7$ is at the N-terminal segment of DDX3 preceding the core helicase domains. Consistent with this notion, the fragment $\mathrm{DDX}_{1-139}$ binds to $\mathrm{K} 7$ in 


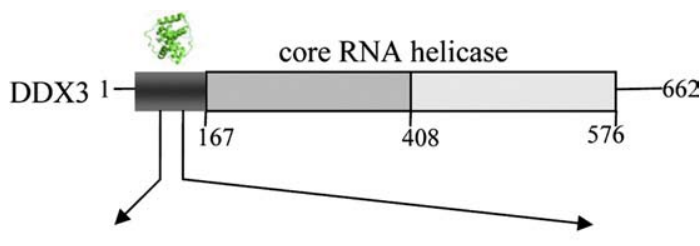

61-SSSKDKDAYS SFGSRSDSRG KSSFFSDRGS-90 $+-+-+-+$

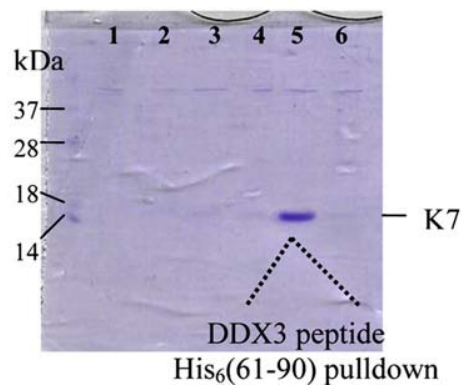

Fig. 7. K7 protein is pulled down by the His-tagged DDX ${ }_{61-90}$ peptide. Top panel: domain organization of human RNA helicase DDX3. Peptides corresponding to the $\mathrm{N}$-terminal region of DDX3 were synthesized with non-cleavable hexahistidine tags. Bottom panel: each lane in the SDS-PAGE gel represents a pull-down experiment using $\mathrm{Ni}^{2+}$-agarose beads. Lane 1, negative control (no proteins added). Lane 2, negative control, untagged K7 was incubated with beads. Lane 3, K7 and DDX $_{1-30}$ peptide were incubated together. Lane 4, K7 and DDX $3_{31-60}$ peptide. Lane 5, K7 and DDX3 ${ }_{61-90}$ peptide. Lane 6, K7 and DDX $3_{121-150}$ peptide. Protein bands were visualized by Coomassie Brilliant Blue. Peptide bands $(4 \mathrm{kDa})$ are too small and weakly staining to be visible in the $12 \%$ SDS-PAGE gel.

HEK293T cells, and the region 1-139 is necessary for the positive effects of DDX3 on ifnb promoter induction. ${ }^{8}$ Biochemical and biophysical studies described here have narrowed an important K7 epitope to the peptide DDX3 $3_{61-90}$. From an electrostatic point of view, there is compatibility, given that the $\mathrm{pI}$ of $\mathrm{DDX} 3_{61-90}$ is 9.5 , while the $\mathrm{p} I$ of $\mathrm{K} 7$ is 4.8 . Collectively, these studies point to the negatively charged face of $\mathrm{K} 7$ as the prime candidate for DDX3 binding (Fig. 6). Several aspartate residues on this face of $\mathrm{K} 7$ are not conserved in A52 (Fig. 2), which may partly explain the inability of A52 to interact with DDX3 despite significant sequence (and presumably structural) similarities to K7.

K7 joins a growing list of viral proteins that target DDX3 to subvert cellular processes for viral replication. Human immunodeficiency virus 1 (HIV-1) has been found to hijack cellular DDX3 via interactions with Rev/CRM-1 to facilitate export of viral mRNA from the nucleus to the cytosol. ${ }^{23}$ Poxviruses are large double-stranded DNA viruses that replicate in the cytosol and therefore do not require the shuttling of nascent viral mRNA from the nucleus. It is possible that different viruses may co-opt distinct regulatory functions of DDX3 and may therefore bind to different regions of the helicase. Consistent with this idea, the interactions between Rev/CRM-1 and DDX3 have been roughly mapped to residues 260517 of DDX3. ${ }^{23}$

Due to the emerging importance of viral and cellular RNA helicases during infection, it has been suggested that they may represent a new class of therapeutic targets for structure-based drug design.9,24 However, our deletion analyses suggest that poxviruses may hijack functions of DDX3 that are independent of RNA substrate binding and ATP hydrolysis. Recently published studies in the laboratory of one of the authors have established a role for DDX3 in ifnb promoter induction through direct binding to $\mathrm{TBK} 1 / \mathrm{IKK} \varepsilon$, thus providing a rationale for the ability of $\mathrm{K} 7$ to inhibit interferon induction via binding to DDX3. ${ }^{8}$ The critical role of DDX3 in the activation of TBK1/IKK $\varepsilon$ has been simultaneously characterized by an independent group. ${ }^{25}$ Future structural characterization of the K7-DDX3 complex, together with biophysical and functional studies, will enable an understanding of the molecular basis for $\mathrm{K} 7$ antagonism of innate immune signaling.

\section{Materials and Methods}

\section{Protein expression and purification}

K7 was PCR-amplified from genomic DNA derived from VACV strain WR, while DDX3 was amplified from cDNA obtained from peripheral blood monocytes. The initial K7 construct for bacterial expression was PCR amplified from a pCMV-Ha-K7 construct (see primers below) and inserted into a modified $\mathrm{pET}$ vector containing an $\mathrm{N}$-terminal His-tag and recombinant tobacco etch virus (rTEV) cleavage site (pHIS-parallel-2, Amp+). The amino acid sequence following cleavage of the affinity tag, GAMGSGIQ-[M1-A2-T3...] began with seven non-native residues prior to Met1 of K7. Since initial NMR spectra suggested that $\mathrm{K} 7$ residues Met1-Tyr7 are flexible, a new construct was designed to dispense with the presumably disordered N-terminus. Following rTEV cleavage, the N-terminally truncated $\mathrm{K} 7$ protein contained the nonnative sequence Gly-Ala-Met arising from the cloning site in the vector, followed by Tyr8-Glu9-Asp10..., etc.

Biophysical and biochemical studies of wild-type fulllength protein were performed using a construct synthesized by GENEART AG (Regensburg, Germany). The coding region (residues 1-149), optimized for Escherichia coli expression, was inserted into pET15b at the Nde1/ BamH1 site. The vector contains an N-terminal His-tag, and following thrombin cleavage, the N-terminus is left with three non-native residues (Gly-Ser-His) prior to Met1 of K7. DDX3 constructs were PCR-amplified using various primers corresponding to truncations of the full-length (662-residue) protein. All DDX3 constructs were cloned into pET-28b with an N-terminal hexahistidine tag, thrombin cleavage site, and a kanamycin resistance marker. In addition to these in-house constructs, customized genes corresponding to fragments 5-167 of DDX3 were synthesized by GENEART and inserted into the Nde1/EcoR1 site of pET28b.

The primers for the initial $\mathrm{K} 7$ construct were $5^{\prime}$-ccggaattcagatggcgactaaattagattat-3' (forward) and $5^{\prime}$-acgcgtcgactcaattcaattt-ttttctag-3' (reverse). The PCR product was cut 
(a)

Time $(\mathrm{min})$

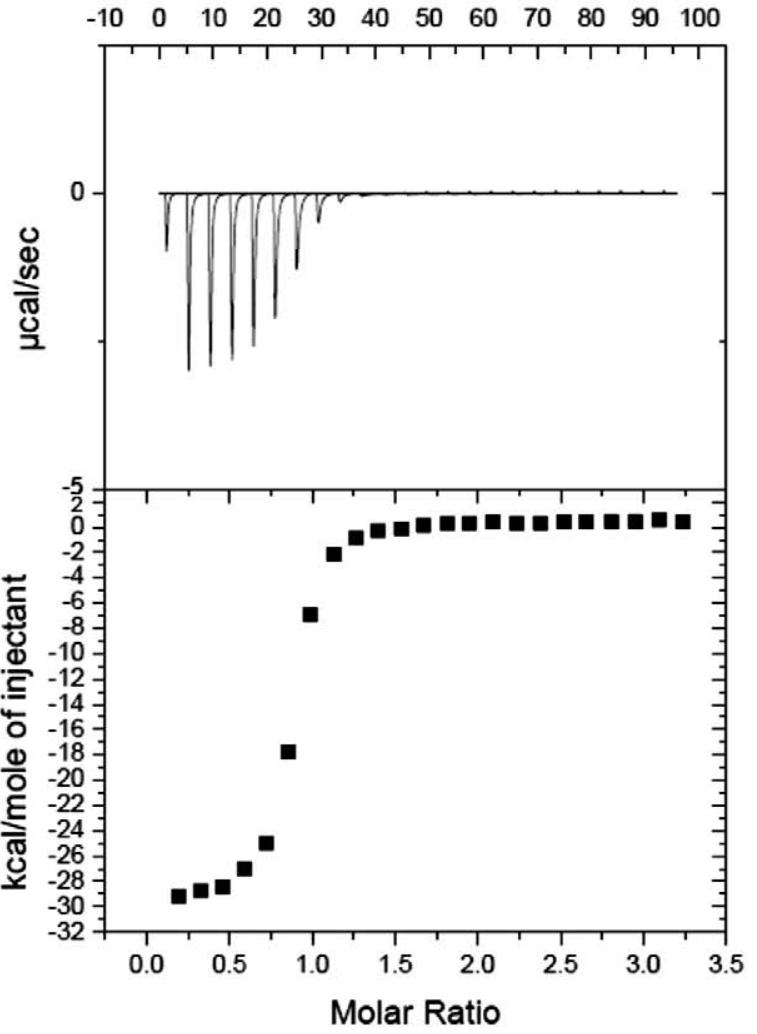

(b)

Time (min)

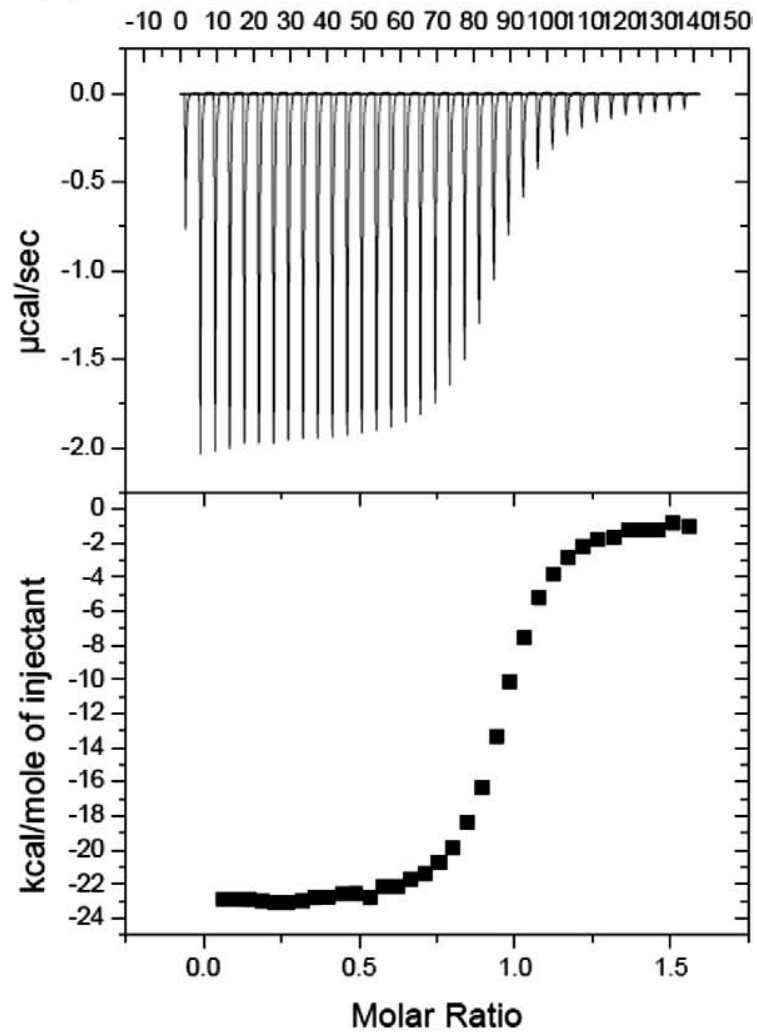

Fig. 8. Calorimetry studies of K7 binding to DDX3. (a) Full-length K7 (400 $\mu \mathrm{M})$ was injected into DDX3 ${ }_{5-167}(17 \mu \mathrm{M})$ in the sample cell. Data were fit using Origin software version 7.0 and the $K_{\mathrm{d}}$ was estimated at $109 \mathrm{nM}$. (b) Hexahistidinetagged DDX3 peptide 61-90 $(250 \mu \mathrm{M})$ was injected into the sample cell containing full-length $\mathrm{K} 7(30 \mu \mathrm{M})$. The $K_{\mathrm{d}}$ was $228 \mathrm{nM}$, demonstrating that this peptide largely retains its affinity to K7, relative to DDX3 ${ }_{5-167}$. The stoichiometry deduced from data fitting is (a) 1.01 and (b) 0.96 .

with EcoR1 and Sal1 and pasted into a modified $\mathrm{pET}$ vector containing an N-terminal His-tag and rTEV cleavage site (pHIS-parallel-2, Amp + ). A forward primer, $5^{\prime}$-catgccatggcgactaaattagattatgagg- $3^{\prime}$, and a reverse primer, $5^{\prime}$-ccggaattctcaattcaattttttttaga-aaaagtatc- $3^{\prime}$, were used to amplify the segment Glu8-Asn149 of K7 into the Nco1/Eco1 site of the modified $p E T$ vector, $p H i s-p a r a l l e l-2$. DDX 3 constructs were PCR-amplified with forward primer 5 '-catgccatgggt-
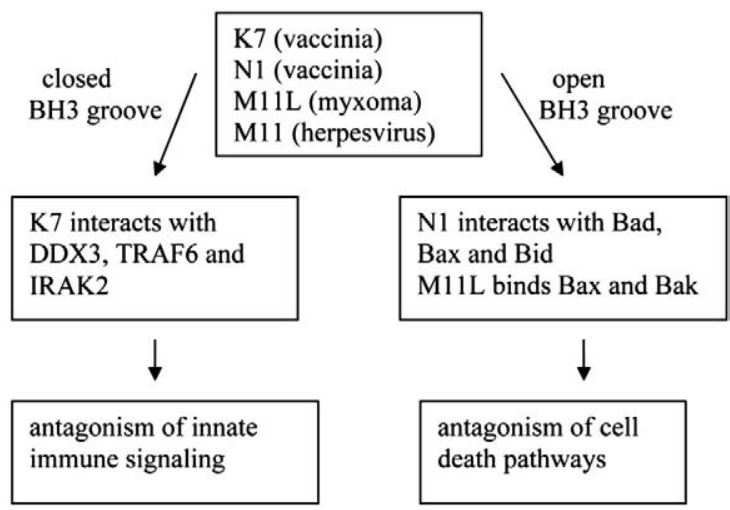

Fig. 9. Viral proteins that adopt the Bcl-2 fold. The family can be subdivided into two structural groups, those that have a closed $\mathrm{BH} 3$ groove (K7, and likely A52, whose structure is currently unknown) and N1/M11/M11L, which have open grooves. catgtggcagtggaaaatgc-3' (Nco1, from Met1); 5'-gggaattccatatgagtcatgtggcagtggaaaatg-3' (Nde1, from Met1); 5'gggaattcc-atatgaactcttcagataatcagagt-3' (Nde1, from Asn22); 5'-gggaattccatatgagtgattacgatggcattg-gcag-3' (Nde1, from Ser102). Reverse primers were $5^{\prime}$-cggaattctcatctggcaccaaaccctccact-3' (EcoR1, Tyr580); 5'-cggaattctcaaatgtcatcgtatttctcaaaattaat-3' (EcoR1, Ile166). All DDX3 constructs were cloned into $\mathrm{pET}-28 \mathrm{~b}$ (Kan+ resistance).

Recombinant protein expression was performed in $E$. coli BL21(DE3) cells. For ${ }^{15} \mathrm{~N},{ }^{13} \mathrm{C}$ and ${ }^{15} \mathrm{~N}$ labeling, cells were grown in minimal salt medium containing $1 \mathrm{~g} / \mathrm{L}$ ${ }^{15} \mathrm{NH}_{4} \mathrm{Cl}$ and $1 \mathrm{~g} / \mathrm{L}{ }^{15} \mathrm{NH}_{4} \mathrm{Cl}$ plus $2 \mathrm{~g} / \mathrm{L}{ }^{13} \mathrm{C}$-substituted glucose respectively. Induction was performed with $0.5 \mathrm{mM}$ IPTG at $37{ }^{\circ} \mathrm{C}$ when $A_{600}$ reached 0.60 , and cells were allowed to grow with vigorous shaking for $3 \mathrm{~h}$. Cells were harvested at $4000 \mathrm{rpm}$ for $10 \mathrm{~min}$, and pellets were solubilized in extraction buffer $(10 \mathrm{mM}$ Tris-Cl, $300 \mathrm{mM}$ $\mathrm{NaCl}, 10 \mathrm{mM}$ imidazole, $10 \mathrm{mM}$ 2-mercaptoethanol, $\mathrm{pH}$ 8.0). Following brief sonication, the lysate was applied over a $\mathrm{Ni}^{2+}$-agarose resin (Chromatrin Inc) and eluted in extraction buffer supplemented with $200 \mathrm{mM}$ imidazole. Fractions of $\mathrm{K} 7$ were combined and dialyzed overnight (10 mM Tris-Cl, $150 \mathrm{mM} \mathrm{NaCl}, 10 \mathrm{mM}$ 2-mercaptoethanol) in the presence of catalytic amounts of rTEV or thrombin, depending upon the construct. The solution containing cleaved $\mathrm{K} 7$ protein was adjusted to $300 \mathrm{mM}$ $\mathrm{NaCl}$ and $10 \mathrm{mM}$ imidazole and reapplied on a $\mathrm{Ni}^{2+}$ agarose column to eliminate uncleaved protein and the rTEV protease (uncleavable N-terminal His-tag). In contrast to $\mathrm{K} 7$, the eluted DDX3 proteins were highly prone to 
aggregation following elution from the $\mathrm{Ni}^{2+}$-agarose columns. In order to stabilize DDX3 proteins, the elution buffer (10 mM Tris-Cl, $300 \mathrm{mM} \mathrm{NaCl}, 10 \mathrm{mM}$ imidazole, $10 \mathrm{mM}$ 2-mercaptoethanol) was supplemented with $10 \%$ glycerol.

\section{Gel-filtration chromatography}

The complex of K7 and DDX $3_{5-167}$ was purified using a Superdex-75 column and an ÄKTAbasic FPLC system (GE Healthcare). Following separate expression and $\mathrm{Ni}^{2+}$ affinity purification, approximately $3 \mathrm{mg}$ of each protein was mixed together and the solution was applied to the FPLC column. The complex was eluted in Tris-buffered saline (10 mM Tris-Cl, $100 \mathrm{mM} \mathrm{NaCl}, 1 \mathrm{mM}$ DTT, pH 7.5). Glycerol addition was not necessary for DDX3 ${ }_{5-167}$ following incubation with $\mathrm{K} 7$, as the complex was stable for days at room temperature. The His-tags ahead of K7 and DDX $_{5-167}$ were not removed prior to gel filtration in this experiment.

\section{In vitro pull-down experiments}

Peptides corresponding to residues 1-30, 31-60, 61-90, 91-120 and 121-150 were synthesized by EMC Microcollections $\mathrm{GmbH}$ (Tübingen, Germany). Each peptide was extended at the $\mathrm{N}$-terminus by a hexahistidine tag (uncleavable). The wild-type K7 construct used for this experiment was synthesized by GENEART (see above). Protein expression was induced at $30{ }^{\circ} \mathrm{C}$ and subsequently purified using routine protocols. His-tag cleavage was facilitated by incubation with thrombin overnight concomitant with dialysis $(10 \mathrm{mM}$ Tris-Cl, $300 \mathrm{mM} \mathrm{NaCl}, 10 \mathrm{mM}$ imidazole, pH 7.7, supplemented with $10 \mathrm{mM} \beta-\mathrm{ME})$. Following brief incubation (30 min) at room temperature, the salt concentration was raised to $300 \mathrm{mM}$, and $\mathrm{Ni}^{2+}$-agarose was added to the cleaved protein and incubated with gentle shaking for $30 \mathrm{~min}$ at $4{ }^{\circ} \mathrm{C}$. The untagged $\mathrm{K} 7$ protein was eluted using a gravity column. The peptides ( $1 \mathrm{mg}$ powder) were dissolved in $1 \mathrm{~mL}$ extraction buffer, and $20 \mu \mathrm{L}$ of this solution was mixed with $30 \mu \mathrm{g}$ of $\mathrm{K} 7 \mathrm{in}$ a total volume of $1 \mathrm{~mL}$ extraction buffer. $\mathrm{Ni}^{2+}$-agarose was added to the mixture of peptide-K7 (40 $\mu \mathrm{L}$ of a $50 \%$ suspension) and the solutions were incubated at $4{ }^{\circ} \mathrm{C}$ with gentle shaking. The $\mathrm{Ni}^{2+}$-agarose was washed three times with $1 \mathrm{~mL}$ extraction buffer to eliminate loosely bound proteins.

\section{NMR spectroscopy and structure determination}

Initial NMR experiments were performed with Histagged full-length K7 protein. From these, it was noted that the chemical shifts of the first few $\mathrm{N}$-terminal residues were at random coil positions. An N-terminal truncated construct $(K 7 \Delta 8)$ had superior NMR characteristics and was chosen for structure determination. Samples of $0.8 \mathrm{mM}{ }^{15} \mathrm{~N}$ and $0.8 \mathrm{mM}{ }^{15} \mathrm{~N},{ }^{13} \mathrm{C}$-labeled $\mathrm{K} 7 \Delta 8$ in $10 \mathrm{mM}$ sodium phosphate, $100 \mathrm{mM} \mathrm{NaCl}, 10 \mathrm{mM}$ DTT, pH 7.0, 90\% $\mathrm{H}_{2} \mathrm{O} /$ $10 \% \mathrm{D}_{2} \mathrm{O}$ were used for NMR experiments. Spectra were recorded at $25^{\circ} \mathrm{C}$ on a Varian Inova $600 \mathrm{MHz}$ with a room temperature probe or a Varian Inova 750-MHz spectrometer equipped with a cryogenic probe. Sequential assignment, structural restraint and structure calculation procedures are detailed in Supplementary Methods online.

The minimum changes in chemical shift between the ${ }^{1} \mathrm{H}-{ }^{15} \mathrm{~N}$ spectra of apo-K7 and the complex K7/DDX3 acquired on $0.1 \mathrm{mM}$ samples of both proteins were calcu- lated by finding for each peak in the apo spectrum the closest peak in the spectrum of the K7/DDX3 complex using the distance metric ${ }^{22} \Delta=\left[\left(\delta^{15} N_{\text {apo }} / \mathrm{k} 7 \mathrm{r}-\mathrm{dd} \times 3\right)^{2}+(5 \times \delta\right.$ $\left.\left.{ }^{1} \mathrm{H}_{\mathrm{apo} / \mathrm{k} 7 \mathrm{r}-\mathrm{dd} \times 3}\right)^{2}\right]^{0.5}$. The environment of residues with a $\Delta>0.5 \mathrm{ppm}$ was then considered to have changed significantly and these residues are thus in the interface between the two proteins. Chemical shift referencing between the two spectra were verified from the chemical shifts from the $10 \%$ of peaks with the lowest value of $\Delta$.

\section{Isothermal titration calorimetry}

Calorimetry was performed using a VP-ITC calorimeter (Microcal Corp). Due to the instability of DDX3 ${ }_{5-167}$, its concentration was maintained below $50 \mu \mathrm{M}$ in the cell. In addition, the titrations were performed in the presence of 10\% glycerol. The DDX3 peptide 61-90 was synthesized with a hexahistidine tag at the N-terminus by EMC Microcollections. The sequence of the peptide was $\mathrm{HHHHHH}-$ SSSKDKDAYSSFGSRSDSRGKSSFFSDRGS. The HPLCpurified peptide was analyzed by mass spectrometry and judged to be better than $95 \%$ pure. The K7 protein used for calorimetry was expressed from a synthetic gene obtained from GENEART (see above). Similarly, the construct DDX3 $_{5-167}$ was obtained from GENEART in the pET-28b vector.

\section{Protein Data Bank accession numbers}

Coordinates of $\mathrm{K} 7$ have been deposited in the PDB and BioMagResBank with accession numbers 2k36 and 15740 respectively.

\section{Acknowledgements}

This work was supported by Science Foundation Ireland (grant 05/RFP/BIC0004 to ARK), and by The University of Leeds.

\section{Supplementary Data}

Supplementary data associated with this article can be found, in the online version, at doi:10.1016/ j.jmb.2008.09.048

\section{References}

1. Smith, G., Chan, Y. \& Howard, S. (1991). Nucleotide sequence of $42 \mathrm{kbp}$ of vaccinia virus strain WR from near the right inverted terminal repeat. J. Gen. Virol. 72, 1349-1376.

2. Bowie, A. (2007). Translational mini-review series on Toll-like receptors: recent advances in understanding the role of Toll-like receptors in anti-viral immunity. Clin. Exp. Immunol. 147, 217-226.

3. O'Neill, L. (2006). How Toll-like receptors signal: what we know and what we don't know. Curr. Opin. Immunol. 18, 3-9.

4. Jin, M. S., Kim, S. E., Heo, J. Y., Lee, M. E., Kim, H. M., Paik, S. G. et al. (2007). Crystal structure of the TLR1TLR2 heterodimer induced by binding of a triacylated lipopeptide. Cell, 130, 1071-1082. 
5. Marshak-Rothstein, A. \& Rifkin, I. (2007). Immunologically active autoantigens: the role of toll-like receptors in the development of chronic inflammatory disease. Annu. Rev. Immunol. 25, 419-441.

6. Maloney, G., Schroder, M. \& Bowie, A. (2005). Vaccinia virus protein A52R activates p38 mitogen-activated protein kinase and potentiates lipopolysaccharideinduced interleukin-10. J. Biol. Chem. 260, 30838-30844.

7. Stack, J., Haga, I., Schroder, M., Bartlett, N., Maloney, G., Reading, P. et al. (2005). Vaccinia virus protein A46R targets multiple Toll-like-interleukin-1 receptor adaptors and contributes to virulence. J. Exp. Med. 201, 1007-1018.

8. Schröder, M., Baran, M. \& Bowie, A. G. (2008). Viral targeting of DEAD box protein 3 reveals its role in TBK1/IKKepsilon-mediated IRF activation. EMBO J. 27, 2147-2157.

9. Kwong, A., Rao, B. \& Jeang, K.-T. (2005). Viral and cellular RNA helicases as antiviral targets. Nat. Rev. Drug Discov. 4, 845-853.

10. Linder, P., Lasko, P., Ashburner, P., Leroy, P., Nielsen, P., Nishi, K. et al. (1989). Birth of the D-E-A-D Box. Nature, 337, 121-122.

11. Yang, Q. \& Jankowsky, E. (2006). The DEAD-box protein Ded1 unwinds RNA duplexes by a mode distinct from translocating helicases. Nat. Struct. Mol. Biol. 13, 981-986.

12. Bono, F., Ebert, J., Lorentzen, E. \& Conti, E. (2006). The crystal structure of the Exon Junction Complex reveals how it maintains a stable grip on mRNA. Cell, 126, 713-725.

13. Cooray, S., Bahar, M. W., Abrescia, N. G., McVey, C. E., Bartlett, N. W., Chen, R. A. et al. (2007) Functional and structural studies of the vaccinia virus virulence factor N1 reveal a Bcl-2-like antiapoptotic protein. J. Gen. Virol. 88, 1656-1666.

14. Aoyagi, M., Zhai, D., Jin, C., Aleshin, A., Stec, B., Reed, J. \& Liddington, R. (2007). Vaccinia virus N1L protein resembles a B cell lymphoma-2 (Bcl-2) family protein. Protein Sci. 16, 118-124.

15. Potterton, L., McNicholas, S., Krissinel, E., Gruber, J., Cowtan, K., Emsley, P. et al. (2004). Developments in the CCP4 molecular-graphics project. Acta Crystallogr. Sect. D: Biol. Crystallogr. 60, 2288-2294.
16. Kvansakul, M., van Delft, M. F., Lee, E. F., Gulbis, J. M., Fairlie, W. D., Huang, D. C. \& Colman, P. M. (2007). A structural viral mimic of prosurvival Bcl-2: a pivotal role for sequestering proapoptotic Bax and Bak. Mol. Cell, 25, 933-942.

17. Ku, B., Woo, J. S., Liang, C., Lee, K. H., Hong, H. S. E. X., Kim, K. S. et al. Structural and biochemical bases for the inhibition of autophagy and apoptosis by viral Bcl-2 of murine g-herpesvirus 68 . PLoS Pathog. 4, e25.

18. Petros, A. M., Olejniczak, E. T. \& Fesik, S. W. (2004). Structural biology of the Bcl-2 family of proteins. Biochim. Biophys. Acta, 1644, 83-94.

19. Liu, X., Dai, S., Zhu, Y., Marrack, P. \& Kappler, J. W. (2003). The structure of a Bcl-xL/Bim fragment complex: implications for Bim function. Immunity, 19, 341-352.

20. Hogbom, M., Collins, R., van den Berg, S., Jenvert, R.-M., Karlberg, T., Kotenyova, T. et al. (2007). Crystal structure of conserved domains 1 and 2 of the human DEAD Box helicase DDX3 in complex with the mononucleotide AMP. I. Mol. Biol. 273, 150-159.

21. Farmer, B. T., II, Constantine, K. L., Goldfarb, V., Friedrichs, M. S., Wittekind, M., Yanchunas, J. et al. (1996). Localizing the $\mathrm{NADP}^{+}$binding site on the MurB enzyme by NMR. Nat. Struct. Biol. 3, 995-997.

22. Williamson, R., Carr, M. D., Frenkiel, T., Feeney, J. \& Freedman, R. (1997). Mapping the binding site for matrix metalloproteinase on the N-terminal domain of the tissue inhibitor of metalloproteinase-2 by NMR chemical shift perturbation. Biochemistry, 36, 13882-13889.

23. Yedavalli, V. S. R. K., Neuveut, C., Chi, Y. H., Kleiman, L. \& Jeang, K. T. (2004). Requirement of DDX3 DEAD box RNA helicase for HIV-1 REV-RRE export function. Cell, 119, 381-392.

24. Xu, G. X. (2007). Helicases as antiviral and anticancer drug targets. Curr. Med. Chem. 14, 883-915.

25. Soulat, D., Burckstrummer, T., Wetsermayer, S., Goncalves, A., Bauch, A., Stefanovic, A. et al. (2008). The DEAD-box helicase DDX3X is a critical component of the TANK-binding kinase 1-dependent innate immune response. EMBO J. 27, 2135-2146. 